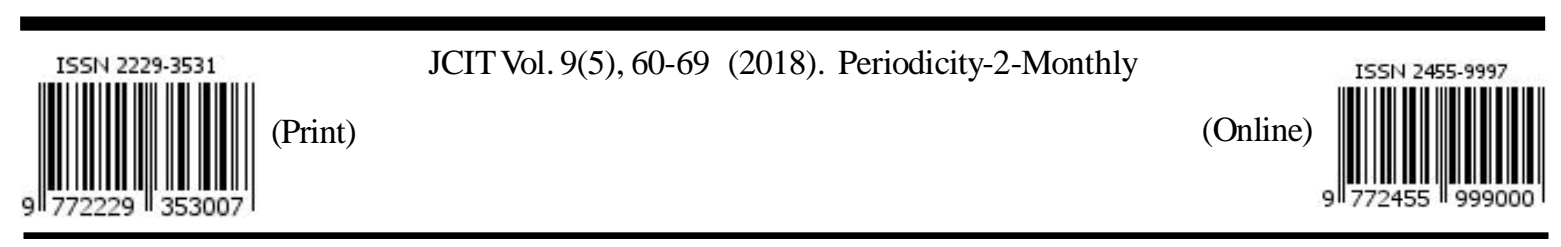

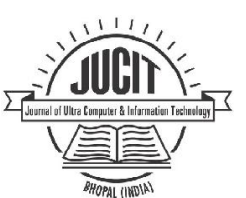

Estd. 2010

JOURNAL OF COMPUTER \& INFORMATION TECHNOLOGY An International Open Free Access Peer Reviewed Research Journal of Computer Science Engineering \& Information Technology website:- www.compitjournal.org

\title{
Design and Implementation of Traffic Light Control by Emergency Service Vehicles
}

\author{
SAFWANA HAQUE ${ }^{1}$ and BOUKARI SOULEY ${ }^{2}$ \\ ${ }^{1}$ Department of Computer Science and Engineering, College of Engineering and Technology (CEAT), \\ IUBAT- International University of Business Agriculture and Technology, Bangladesh, Dhaka, Bangladesh \\ ${ }^{2}$ Department of Mathematical Sciences, Abubakar Tafawa Balewa University (ATBU), Bauchi, Nigeria \\ Email address of Corresponding Author: safwanahaque@gmail.com \\ http://dx.doi.org/10.22147/jucit/090503
}

Acceptance Date 04th October 2018

Online Publication Date 16th October, 2018

\begin{abstract}
In today's world, cities have become crowded with a lot of vehicles, which have lead to congestions on the roads. The time spent in traffic jams has greatly increased and this has become not only an annoying problem but also poses a very difficult problem to emergency service vehicles like the ambulances, fire services, etc. which cannot get to their destinations in time. They are to wait for the roads to be cleared and by the time they get to their destinations, it might just be too late to do anything useful. This study was therefore aimed at solving this problem by designing a means of allowing emergency service vehicles to be able to control the traffic signal so as to reduce the time spent in road junctions by changing the traffic light signal from red to green along the lanes. The circuitry of this work comprises digital IC components like timers and operational amplifiers. It also has other components like diodes, resistors, capacitors, transformers, transistors, LEDs and microphone. The entire system was initially constructed on a bread board and then transferred to a vero board. It consisted of four units: the power supply, the logic control, the detection and the traffic light display units. At each stage of the circuit construction, tests were carried out to verify that they were working and giving the expected output.

Key words : Traffic light control, Emergency service vehicle, Traffic signal Pre-emption.

\section{Introduction}

Traffic lights are signalling devices that are positioned at road intersections, pedestrian crossings or two or more roadways to control the competing flows of vehicle and human traffic in an orderly manner without which the busy roads would be chaotic. This is achieved by providing a visual indication to drivers when to proceed, when to slow down, when to stop and at times when to

take a turn.

Traffic lights are installed in almost all the cities in the world to control the flow of traffic. They are used to assign the right of way to road users by the use of lights in standard colours (Red Amber Green). They are very useful at busy intersections which are used to evenly apportion delay to the various users on different lanes. These signals may be operated manually or by a simple timer which allows traffic to flow on one roadway for a fixed period of time,
\end{abstract}

This is an open access article under the CC BY-NC-SA license (https://creativecommons.org/licenses/by-nc-sa/4.0) 
and then on the other road-way for another fixed period of time before repeating the cycle. Other signals may be operated by sophisticated electronic controllers that sense the time of day and flow of traffic to continually adjust the sequence of operation of the signals. Traffic engineers use signals to avoid traffic congestion and improve safety for both motorists and pedestrians.

Traffic light technology is constantly evolving with the aims of improving reliability, visibility, efficiency, control and coordination of traffic flow. The need for traffic management strategies are as follows - due to increase in travel demand in urban areas, lack of additional land to expand the transportation system and increase in construction costs etc.

One such traffic management strategy is the use of signal priority techniques at road intersections. Signal priority is the technique of changing or maintaining a traffic signal display in order to reduce the amount of stopped delay for targeted vehicles, like emergency vehicles. This is usually achieved by providing continuous green light to these vehicles whenever they approach an intersection.

In almost every emergency callout for the services of such vehicles, dangerous situations arise, especially when crossing intersections and when using opposite lanes too. These situations may lead to serious accidents, if not properly coordinated. In city/urban traffic, such a call-out requires the use of continuous sirens. Such emergency vehicles are usually exempted from the road traffic rules and regulations when they are fitted with sirens and flashing lights. But the use of sirens leads to an almost intolerable levels of noise pollution, especially if the frequency of these emergency vehicles is high. However, journey speeds of emergency vehicles have become lower as the traffic density has increased with cross street traffic impeding these journeys. Hence signal-setting strategies, to give priority to emergency vehicles, have become necessary to give unimpeded passage to these vehicles at signalized intersections and to stop all cross-street and opposing traffic.

\section{Literature Review :}

\subsection{Historical Background of Traffic Light Controller :}

The need for traffic control started even before the invention of automobiles. Then the traffic consisted of wagons, horse carts, bicycles and pedestrians only, but this on its own caused problems at busy road intersections. To control the traffic, police officers were assigned at the intersections to control the flow of traffic. It was during this time, in mid-nineteenth century, that the first traffic light came into being. The traffic lights were installed at an intersection in London on the 10th of December 1868 by a railway engineer J. P. Knight ${ }^{1}$. The traffic lights were more like the railway signals of that era, with red and green gas lamps operated with a lever such that the appropriate light faced the approaching traffic. Unfortunately it exploded on 2nd January 1869 injuring the policeman operating $i^{2}$.

The modern electric traffic light is an American invention. In as early as 1912 in Salt Lake City, Utah, policeman Lester Farnsworth Wire invented the first redgreen electric traffic lights ${ }^{3}$. On 5th August 1914, the American Traffic Signal Company installed a traffic signal system on the corner of East 105th Street and Euclid Avenue in Cleveland, Ohio. It had two colours red and green and a buzzer, based on the design of James Hoge, to provide a warning for colour changes ${ }^{4}$. The design by James Hoge allowed police and fire service vehicles to control the signals in case of emergency.

With the invention of automobiles, the traffic situation got worse and that is when a police officer William L. Potts of Detroit, Michigan, decided to do something about the problem. He adapted the use of railroad signals for street use as they were different since railroad traffic travelled along parallel lines and street traffic at right angles. With the use of red, amber and green railroad lights, he created the world's first 4way three coloured traffic light and it was installed in $1920^{5}$. In 1923, Garrett Morgan patented a traffic signal device. It was Morgan's experience while driving along the streets of Cleveland that led to his invention of a traffic signal device. Ashville, Ohio, claims to be the location of the oldest working traffic light in the United States, used at an intersection of public roads until 1982 when it was moved to a local museum. The first interconnected traffic signal system was installed in Salt Lake City in 1917, with six connected intersections controlled simultaneously from a manual switch. Automatic control of interconnected traffic lights was introduced in March 1922 in Houston, Texas. The first automatic experimental traffic lights in England were deployed in Wolverhampton in $1927^{6}$.

A modern traffic signal system consists of three basic subsystems: the signal lights in their housing, the supporting arms or poles, and the electric controller. The signal lights and housing are known as the signal light stack. A single stack usually consists of three lights: a green light on the bottom to indicate that the traffic may proceed, a yellow light in the middle to warn traffic to slow and prepare to stop, and a red light on the top to indicate the traffic to stop. Because some people are red-green colour blind, there has been an effort to standardize on a vertical stack of lights with red at the top so that these people can perceive the signal condition by the position of the light rather than the colour. Each light has a Fresnel lens which may be surrounded or hooded by a visor to make it easier to see the light in 
bright sunlight. A Fresnel lens consists of a series of concentric angled ridges on the outer surface of the lens which bend the light to focus it in a parallel beam. The light stack may have a dark-coloured backing plate to make the signals more distinguishable by blocking out surrounding lights from buildings and signs. There are one or more signal light stacks for each direction of each roadway. The electric controller is usually mounted in a weather-proof box on one of the corners of the intersection. More elaborate traffic signals may also have electromagnetic sensors buried in the roadway to detect the flow of traffic at various points. Since the invention of traffic lights, there have been many modifications and improvements but are still based on the same colour standard - red light indicating stop, yellow/ amber to get ready and green light for go.

\subsection{Emergency Service Vehicles :}

An emergency service vehicle is a vehicle that is designated and authorized to respond to an emergency situation like a health emergency, fire accident or crime scenes. These vehicles are usually operated by designated agencies, often part of the government, but also run by charities, non-governmental organizations and also commercial companies. Often emergency vehicles are permitted by law to break conventional traffic rules and regulations in order to reach their destinations in the shortest possible time, for example, driving through an intersection when the traffic light is red, or driving the emergency vehicle beyond the permitted speed limit.

There are many types of emergency vehicles. Some examples are as follows police and security (e.g. police car, police motorcycle, bomb disposal vehicle); fire and rescue (search and rescue team vehicle, hazardous materials team vehicle, lifeguard vehicle); medical (ambulances and ambulance response vehicles, organ transplant or blood supply vehicles). Most of these vehicles that respond to emergency situations have audible (e.g. sirens) and visual warning devices (e.g. flashing lights), which are designed to alert all other vehicles of their approach and usually to give way to the emergency vehicles to facilitate their movement through the traffic to reach their destination and to provide some protection on the scene. Usually, when an emergency vehicle on the road using its warning devices to indicate it has an emergency to attend, all cars by law are required to pull over to the side of the road, stop and wait for the emergency vehicle to pass before resuming normal driving, unless in cases where this could lead to an accident or if stopped at a red light. In areas where no such laws exist, many motorists may allow the vehicle to pass as a sign of courtesy.

\subsection{Traffic Signal Priority/Pre-emption Techniques :}

The use of signal pre-emption is almost as old as the use of traffic light signal itself. The first ever implementation of signal pre-emption started in 1914 with a traffic light designed by James Hoge that allowed emergency vehicles to control the traffic light. Since then, there have been numerous efforts to create pre-emption techniques each having its advantages and disadvantages.

The signal pre-emption methods in existence are generally classified into several categories ${ }^{7,8}$ depending on the technology used for detecting the emergency vehicles. They are as follows: optical, infrared light, acoustic, special types of loop detection and GPS-based systems.

- The optical systems were first developed in the 1960 s and are the most commonly used ones in the field. It uses invisible infrared signals or by strobe lights on the vehicle and an optical sensor per approach to an intersection requiring a clear line-of-sight path between the vehicle and the intersection ${ }^{9}$.

- Light and infrared systems employ emitters that are normally mounted on the roofs of emergency vehicles and are operated in conjunction with the traffic lights. The emitters send visible flashes of light or invisible infrared pulses at a specified frequency. Receiver devices placed on or near intersection traffic control devices recognize the signal and pre-empt the normal cycle of traffic lights. Once the emergency vehicle crosses the intersection and the receiving device can no longer sense the remote triggering device, normal operation resumes. This system is very easy to implement, but it has lead to several problems like flashing of headlights of vehicles continuously at times trigger the receivers and pre-empt the traffic signal. Also, infra-red transmitters are very easy to use and readily available and as such every other person could use them to pre-empt the traffic lights. Another disadvantage of the optical systems is the need for a lineof-sight between the transmitter and receiver for triggering the pre-emption signal. Common obstacles that are inevitable like large vehicles (i.e. trailers, trucks, lorries and buses) or even tree branches, which may overhang roadways can block the line-ofsight transmission thereby preventing the emergency vehicle from pre-empting the traffic signal.

- The sound-based systems use sirens as the emitter which is loaded onto the detection and processing equipment could detect the directional microphones installed at an intersection to detect the siren of vehicles approaching a given intersection, therefore, no special equipment is required for the emergency vehicles ${ }^{10}$. 
- Radio-based systems use receivers with an omnidirectional antenna to detect a digitally coded spread spectrum or narrow band radio transmission from an emergency vehicle. In these systems, the direction of pre-emption is selected in the vehicle and directionunique signal is transmitted to the intersection. Radiobased systems avoid the line-of-sight limitations associated with lightand infrared-based systems. Once a radio frequency pulse is detected and the proper direction of travel is determined, the pre-emption request is sent to the signal controller and then triggers a beeper, or speaks through a loudspeaker, so that the interrogator can find the sound source. At the first thought, this might seem to be a more appealing idea as their radiations have larger coverage areas than infrared beams. Interference between signs could be greatly reduced if frequency modulation (FM) were used enabling only the strongest signals to be heard. However, precise directional information about the location of the sign would not be possible unless a directional receiving antenna was used, and at radio frequencies, such an antenna would be large.

The GPS approach uses the satellite-based Global Positioning System and determines the signal pre-emption time depending on the position, speed, and travel direction of the emergency vehicle approaching an intersection. In a GPS-based system being operated usually both an emergency vehicle and an intersection are equipped with a GPS receiver and a radio transceiver for two-way communication $^{11}$ that helps in determining the vehicle's position (latitude, longitude and altitude), velocity and current time. Even though this is the most efficient technique for signal pre-emption, it has not yet been well developed. It is also very expensive to implement and not readily available to countries other than America and some European countries.

- Another pre-emption technique is the use of a special loop sensor with transponders for emergency vehicle ${ }^{12}$ which is a radio or radar transceiver that automatically transmits a signal of its own when it receives a predetermined signal from elsewhere, used especially for locating and identifying objects. The detection system uses loops (antennas) embedded in the road and transponders on the buses and trams. Special radio frequency readers are installed along the roadside which detect a vehicle when it crosses a demarcated point. The reader sends out a radio frequency signal to the transponder via an antenna (loop) embedded in the road. The transponder then returns a signal that carries the data it stores. This data is a unique e.g. 64 bit, factory programmed identifier. The transmission technique used between the transponder and the reader has pre-defined frequencies e.g. $134.2 \mathrm{kHz}$ and $123.2 \mathrm{kHz}$. The loops have to be placed far enough away from the stop line to allow the signals to react to the presence of the vehicle, but not too far from the stop line, in order to provide an accurate prediction of the arrival time at the stop line.

However, the message carried by a loop cannot be heard from a distance, unless the loop is large enough to encircle that distance; if that were done, then a specific target cannot be localised. Secondly, the modern world is full of noisy alternating magnetic fields which would make noise in the user's receiver as he searches for "signs." Also, a loop is expensive as it needs a large power supply and is difficult to install; if not buried underground, it must be supported overhead in a horizontal plane.

Till date, new systems are being engineered to overcome the shortcomings of the above systems and also utilising the positive capabilities of the existing systems to create pre-emption techniques with enhanced modifications and efficiencies.

\section{Materials and Methods}

\subsection{Materials/Components Used :}

The circuitry of this work comprised of digital IC components like a timer IC (NE555), an operational amplifier (LM741) and a 5-stage Johnson counter (4017). It will also have other components like signal diodes (1N4148), rectifier diodes (1N4001), resistors of various resistances, capacitors of varying capacitances, electret condenser microphone, transformer, LEDs, relays, bread boards for initial testing of the circuit, vero boards for final circuit soldering and connecting wires. Tables 1 and 2 show a brief description and function of each electronic component used in the construction of the traffic light pre-emption circuit.

\subsection{Design Calculations : \\ 3.2.1 Power supply :}

Assuming the current requirement of the circuit is not more than $500 \mathrm{~mA}$ since all the components require a very small amount of current and since relays require $12 \mathrm{~V}$ and the drop out voltage of a voltage regulator is at least $2 \mathrm{~V}$ for proper operation, then average voltage after full wave rectification is:

$\mathrm{V}_{\mathrm{dc}}=2 \mathrm{~V}_{\text {max }} / \pi-2 \mathrm{~V}_{\text {diode }}=2 \sqrt{2} \mathrm{~V}_{\text {rms }} / \pi-2 \mathrm{~V}_{\text {diode }}$

$\mathrm{V}_{\mathrm{dc}}$ is the average voltage of rectified wave $\geq 12 \mathrm{~V}+2 \mathrm{~V}$

$\mathrm{V}_{\text {max }}^{\mathrm{dc}}$ is the peak voltage of rectified sinusoidal wave

$\mathrm{V}_{\text {diode }}^{\text {max }}$ is the voltage drop across a diode $=0.7 \mathrm{~V}$

$14 \leq 2 \sqrt{2} \mathrm{~V}_{\text {rms }} / \pi-2 \mathrm{~V}_{\text {di }}$

$\leq 2 \sqrt{ } 2 \mathrm{~V}_{\mathrm{rms}} / \pi-2(0.7)$

$\mathrm{V}_{\mathrm{rms}} \geq 14+2(0.7) \times \pi / 2 \sqrt{ } 2$

$\mathrm{V}_{\mathrm{rms}}^{\mathrm{rms}} \geq 17.1 \mathrm{~V}$ 
Table 1. Electronic components used in circuit construction

\begin{tabular}{l|l}
\hline Electronic Components & $\begin{array}{l}\text { Quantity/Specification/ } \\
\text { Function }\end{array}$ \\
\hline 555 timer IC & 2 \\
$\begin{array}{l}\text { J017 (5-stage } \\
\text { Johnson counter) IC } \\
\text { LM 741 (operational } \\
\text { amplifier) IC }\end{array}$ & 1 \\
7805 (positive voltage & 1 \\
regulator) IC & 1 \\
7905 (negative voltage & \\
regulator) IC & 1 \\
IC seats & 16 -pin (1), 8-pin (1) \\
LEDs (light emitting diodes) & 4 red, 4 amber, 8 green (for \\
& traffic lights); 2 white (for \\
& timer indicators) \\
1N4148 (signal diodes) & 32 \\
1N4007 (rectifier diodes) & 4 \\
Transformer (12V, 500mA) & 1 \\
Capacitors & $47 \mu \mathrm{F}$ (1) \\
Resistors & $4.7 \mathrm{k}(4), 100 \mathrm{k}$ (2) \\
Vero board & 1 \\
Jumper wires & To connect components to \\
& one another from one point \\
to another across the vero \\
board
\end{tabular}

The transformer closest to this value would be $18 \mathrm{~V}$ i.e $9 \mathrm{~V}-0 \mathrm{~V}-9 \mathrm{~V}$, but due to its unavailability in the market, a $24 \mathrm{~V}$ transformer was used i.e $12 \mathrm{~V}-0 \mathrm{~V}-12 \mathrm{~V}$ with a current rating of $500 \mathrm{~mA}$. The filter capacitor is specified by its voltage and capacitance values. The voltage value is the maximum voltage that can be passed through the capacitor before breakdown occurs. For a $24 \mathrm{~V}$ transformer, the peak voltage of a rectified voltage would be $\sqrt{ } 2 \times 24 \mathrm{~V}=33.9 \mathrm{~V}$ and the most readily available voltage is $50 \mathrm{~V}$. To calculate the capacitance of the capacitor using, $\mathrm{I}=\mathrm{C} \times \Delta \mathrm{V} / \Delta \mathrm{t}$

Using $1 / 2 \mathrm{f}$ for $\Delta \mathrm{t}$ since the filter capacitor would start charging in less than half a cycle, thus

$\Delta \mathrm{V}=\mathrm{I}_{\text {load }} / 2 \mathrm{fC}$, Where Iload is load current in $\mathrm{A}=500$ $\mathrm{mA}, \mathrm{f}$ is the frequency of power supply in $\mathrm{Hz}=50 \mathrm{~Hz}$, $\Delta \mathrm{V}$ is ripple voltage, $\mathrm{C}$ is capacitance of capacitor

Since the less the ripple in a circuit, the better the circuit, then choosing a small ripple percentage of $10 \%$, $\Delta \mathrm{V}=10 \% \times \mathrm{V}_{\mathrm{rms}}=1.71 \mathrm{~V}$

$\mathrm{C}=\mathrm{I}_{\text {load }} / 2 \mathrm{f} \Delta \mathrm{V}=0.5 / 2 \times 50 \times 1.71=2.924 \times 10-3=2924 \mu \mathrm{F}$

The most readily available capacitor whose capacitance is closer to this range is $3300 \mu \mathrm{F}$ or $4700 \mu \mathrm{F}$.
Table 2. Instruments and tools used in circuit construction

\begin{tabular}{l|l}
\hline $\begin{array}{l}\text { Instruments/ } \\
\text { tools used }\end{array}$ & Function \\
\hline $\begin{array}{l}\text { Bread boards } \\
\text { Soldering iron }\end{array}$ & $\begin{array}{l}\text { To make a temporary connection of circuit } \\
\text { A tool with a point that is heated for melting } \\
\text { and applying solder to fix components on } \\
\text { vero boards } \\
\text { A tool that removes/sucks in molten solder } \\
\text { to remove soldered components from vero } \\
\text { board }\end{array}$ \\
Soldering lead & $\begin{array}{l}\text { A metallic alloy that melts at comparatively } \\
\text { low temperature and are used for patching } \\
\text { or joining of metals. }\end{array}$ \\
pong nose & $\begin{array}{l}\text { A hand tool with two hinged arms ending } \\
\text { in jaws that are closed by hand pressure } \\
\text { to grip tiny/small-sized components to } \\
\text { either fix/remove them }\end{array}$ \\
Cutter & $\begin{array}{l}\text { A type of pliers used to cut wires or } \\
\text { component pins }\end{array}$ \\
$\begin{array}{l}\text { Digital } \\
\text { multimeter }\end{array}$ & $\begin{array}{l}\text { An instrument that reads and measures } \\
\text { electrical parameters such as current, } \\
\text { voltage, and resistance } \\
\text { To supply voltage and test circuit } \\
\text { temporarily when on bread board } \\
\text { To cut out parts of vero board where } \\
\text { continuity not required } \\
\text { To design and simulate circuit before } \\
\text { implementing on bread boards and vero } \\
\text { boards }\end{array}$ \\
Razor blade & aftwar
\end{tabular}

\subsubsection{5 timer}

An astable circuit produces a 'square wave'. This is a digital waveform with sharp transitions between low $(0 \mathrm{~V})$ and high $(+\mathrm{Vs})$. The circuit is called an astable because it is not stable in any state: the output is continually changing between 'low' and 'high'. The time period $(\mathrm{T})$ of the square wave is the time for one complete cycle, but it is usually better to consider frequency (f) which is the number of cycles per second.

$\mathrm{T}=0.7 \times(\mathrm{R} 1+2 \mathrm{R} 2) \times \mathrm{C} 1$ and $\mathrm{f}=1.4 /(\mathrm{R} 1+2 \mathrm{R} 2) \times \mathrm{C} 1$, where $\mathrm{T}=$ time period in seconds $(\mathrm{s}), \mathrm{f}=$ frequency in hertz $(\mathrm{Hz}), \mathrm{R} 1=$ resistance in ohms $(\Omega), \mathrm{R} 2=$ resistance in ohms $(\Omega), \mathrm{C} 1=$ capacitance in farads $(\mathrm{F})$

The time period can be split into two parts: $\mathrm{T}=\mathrm{Tm}+\mathrm{Ts}$

Mark time (output high): $\mathrm{Tm}=0.7 \times(\mathrm{R} 1+\mathrm{R} 2) \times \mathrm{C} 1$

Space time (output low): Ts $=0.7 \times \mathrm{R} 2 \times \mathrm{C} 1$ 
$\mathrm{Tm}=0.7 \times(100 \times 103+100 \times 103) \times 47 \times 10-6=6.58 \mathrm{~s}$

Ts $=0.7 \times 100 \times 103 \times 47 \times 10-6=3.29 \mathrm{~s}$

$\mathrm{F}=1.4 /(110+2 \times 110) \times 103 \times 47 \times 10-6=0.101 \mathrm{~s} \mathrm{H} \approx 0.1 \mathrm{~s}$

$\mathrm{T}=\mathrm{Tm}+\mathrm{Ts}$ or $1 / \mathrm{f}=9.87 \mathrm{~s}$

A monostable circuit produces a single output pulse when triggered. It is called a monostable because it is stable in just one state: 'output low'. The 'output high' state is temporary. The duration of the pulse is called the time period $(\mathrm{T})$ and is determined by resistor $\mathrm{R} 1$ and capacitor $\mathrm{C} 1$ :

Time period, $\mathrm{T}=1.1 \times \mathrm{R} 1 \times \mathrm{C} 1$,

$\mathrm{T}=$ time period in seconds $(\mathrm{s}) ; \mathrm{R} 1=$ resistance in ohms $(\Omega)$; $\mathrm{C} 1=$ capacitance in farads $(\mathrm{F})$

$\mathrm{T}=1.1 \times 100 \times 103 \times 100 \times 10-6=11$ seconds

\subsection{Design Construction :}

The circuitry of this design was mainly made up of four sub-units: the power supply unit, the logic control unit of traffic light, the detection unit and the traffic light display unit. The block diagram of the circuitry's sub-units is as shown in Figure 1.

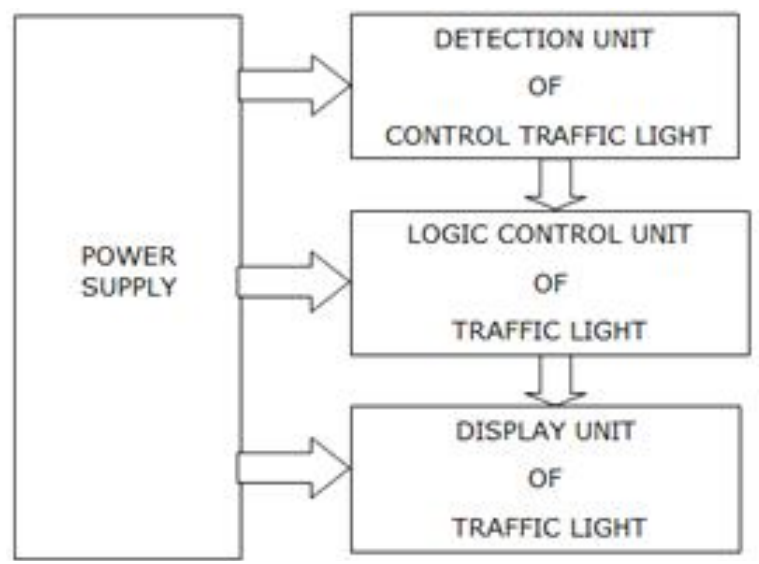

Figure 1. Block diagram of sub-units of the traffic light circuitry

The power supply unit: provides power to the whole circuit. It basically makes use of a transformer, four rectifier diodes, two voltage regulators (7805 and 7905), two capacitors of $3300 \mu \mathrm{F}, 35 \mathrm{~V}$ and connecting wires.
The logic control unit of traffic light: controls the traffic light sequencing, comprises of a 555 timer IC in astable mode, a 5-stage Johnson decade counter, resistors (two 100k and four $4.7 \mathrm{k}$ ), a $47 \mu \mathrm{F}$ capacitor, a relay, 32 signal diodes (1N4148) and connecting wires.

The detection unit: detects the presence of an emergency vehicle's siren sound; comprises of an electrets microphone, an operational amplifier, a 555 timer in monostable mode, transistor, capacitors and resistors of various values and connecting wires.

The traffic light display unit: is traffic light section; basically made up of LEDs of four red, four amber/yellow and eight green colours (four for normal green and four for signal green).

Details of the sub-units and complete circuitry of the traffic light is shown in Figure 2.

\section{TESTS, RESULTS AND DISCUSSION}

\subsection{Tests}

At each stage of the circuit construction, tests were carried out on each sub-unit and also on components such as the various ICs used to verify that they were working and giving the expected output using oscilloscopes and digital multimeters. The various tests carried out were as follows:

The power supply unit: After constructing the power supply unit, it was tested to check if $+5 \mathrm{~V}$ and $-5 \mathrm{~V}$ $\mathrm{dc}$ voltages after regulation and $+12 \mathrm{~V}$ and $-12 \mathrm{~V}$ dc voltages were achieved before regulation. A voltage regulator has three pins - an input pin, an output pin and a ground pin. To test for voltages before regulation, the strobes of a multimeter were placed at the input and ground pins. To check for voltages after regulation, the strobes were placed at the output and ground pins. Also, an oscilloscope was used to check for rectified and filtered voltage level.

The logic control unit: The logic control unit is made up of two important ICs - the 555 timer and 4017 5stage Johnson counter. First, the 555 timer section was constructed to operate in astable mode. After construction, an LED was fitted at the output pin of the 555 timer to check for the proper functioning of the timer's pulses. These pulses are fed into the input pin of the 4017 counter which serves as clock pulses. At each clock pulse, the output pins of the 4017 were expected to go high consecutively. To check for this, four LEDs were placed at the first four output pins since only four lanes were used for this work. 


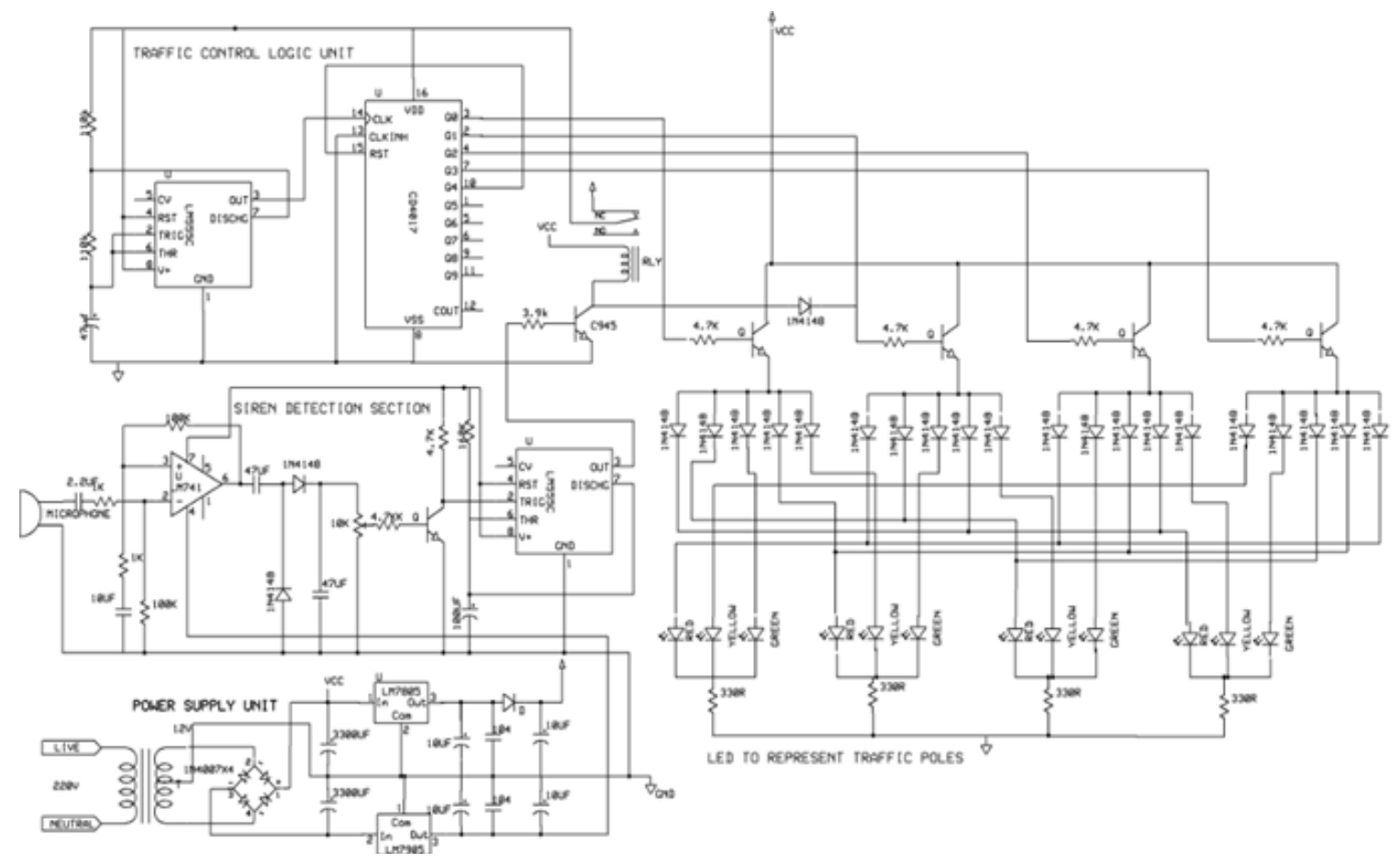

Figure 2. Circuit diagram for traffic light pre-emption vehicle

The detection unit: The microphone of this section was connected to an op-amp which in turn was connected to a 555 timer. An LED was connected to the output of the timer to indicate when a siren is detected.

The traffic light display unit: The LEDs and diodes were placed in their right order before checking if the lighting occurred in the correct sequence.

\subsection{Results and Discussions}

The results obtained after the testing phase are described below.

The power supply unit: After testing, it was observed that the voltage at the positive regulator was in the range of + $4.8 \mathrm{~V}$ to $+5.2 \mathrm{~V}$ while at the negative regulator it was in the range of $-4.8 \mathrm{~V}$ to $-5.2 \mathrm{~V}$. The values obtained are accurate and sufficient for the requirements of the circuitry within the short comings of the regulators.

The logic control unit: The LED at the 555 timer was observed to switch on and off intermittently. This is as expected since the timer was operating in an astable mode. When the LED remained on, it indicated the time period for which the pulse was high which was about 6.6 seconds.

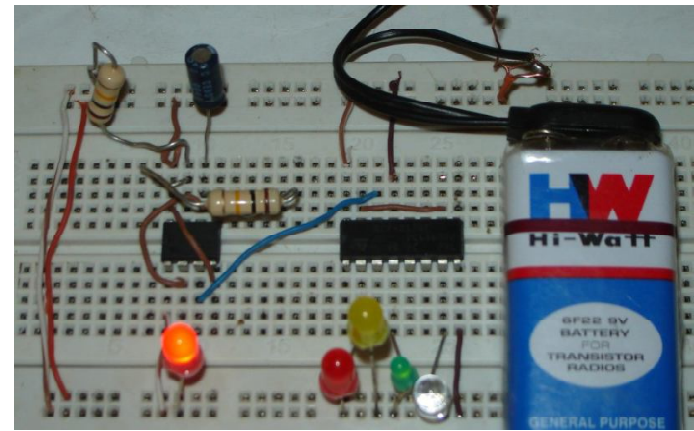

Figure 3. Bread board connection of logic control unit

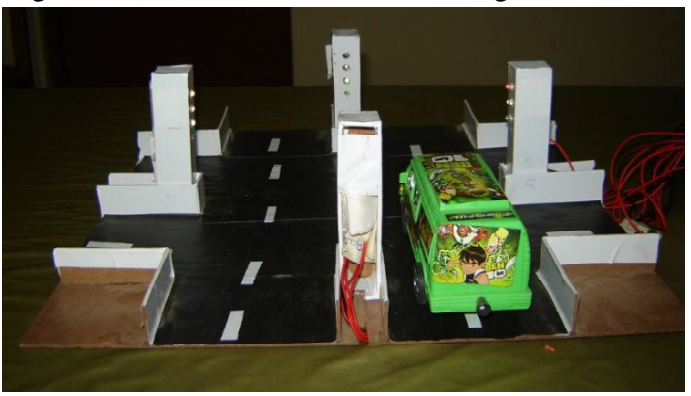

Figure 4. change of lights from red to green on siren detection 
When the LED switched off, it indicated the time period for which the pulse was low which was about 3.3 seconds. The LEDs connected at the output pins of 4017 were observed to go high one at a time starting from pin 3, then pin 2, pin 4 and finally pin 7 . It was observed that at the fifth pulse the first LED at pin 3 would glow again. This is because the fifth output pin was connected to the reset pin which made the counter skip the other pins and restart its count all over again. Figure 3 shows the bread board connection of the logic control unit where the red and white LEDs of the timer and counter respectively are on.

The detection unit: When the microphone in this unit detected a sound, it activated the LED connected at the output pin of the 555 timer. As this timer was set to operate in monostable mode, it issued a high pulse for 11 seconds once it got triggered and in return caused the relay connected to it to switch and activate the green lights on the lane that had an approaching emergency vehicle. Figure 4 shows the change of traffic lights from red to green on the lane that an emergency vehicle approaches.

The traffic light display unit: It was observed that the four transistors connected to the output pins of the 4017 counter got activated one at a time depending on the output pin of the counter. Each transistor represented a lane and the transistor that was active at a particular time activated a series of traffic light at that time which is as shown in Table 3. The vero board transistor connections are shown in Figure 5. The lighting sequence of the traffic light after implementation is shown in Figure 6. The traffic light sequence observed at the four different lanes is as summarised in Table 4. The pictorial representation of the different lanes with their traffic light occurrence at a particular time and the possible vehicle lane movement at that time is as show in Figure 7.

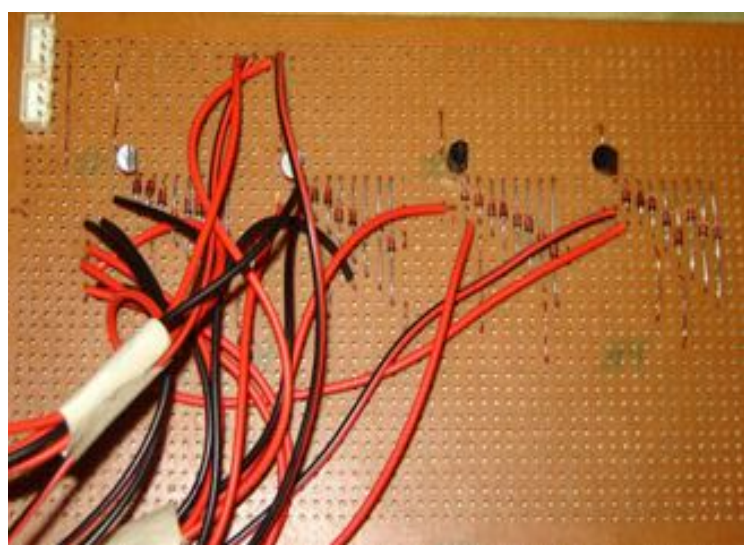

Figure 5: Transistor connections on vero board

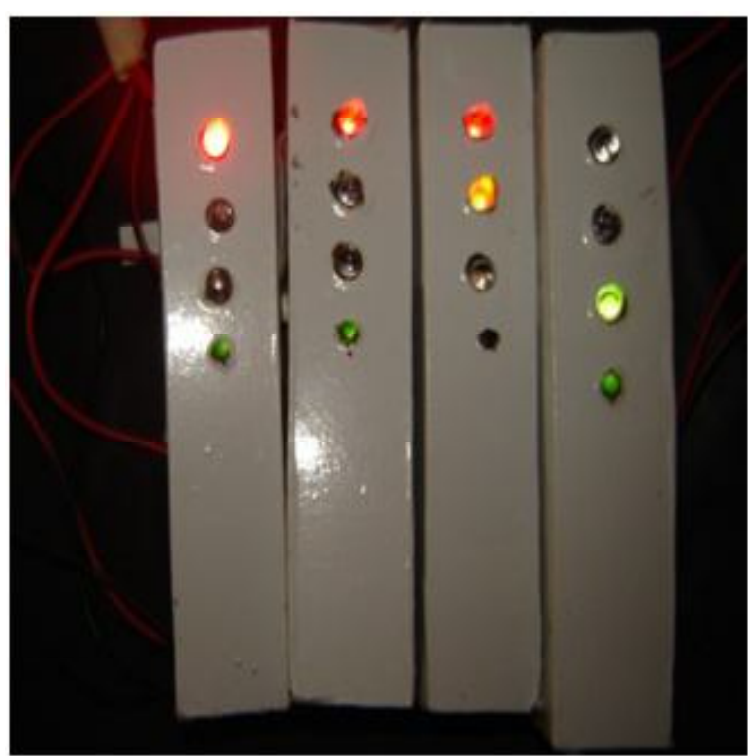

Figure 6. Lighting sequence of the traffic light after implementation
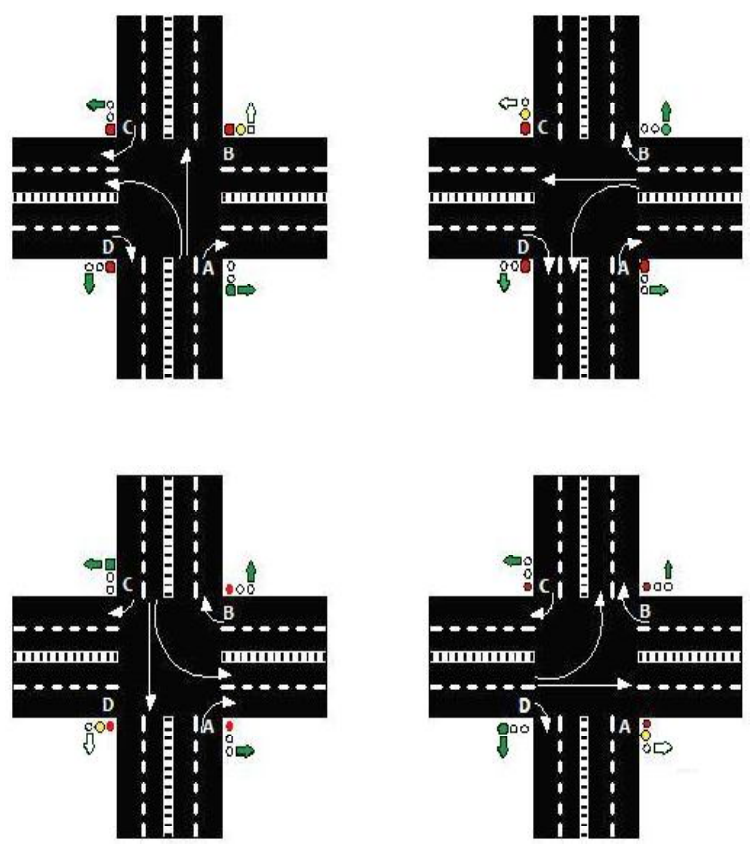

Figure 7. Illustration of traffic light sequence and possible vehicle movements 
Table 3. The LEDs activated by a transistor

\begin{tabular}{|c|c|c|c|}
\hline $\begin{array}{l}1^{\text {st }} \\
\text { Transistor } \\
\text { activates }\end{array}$ & $\begin{array}{l}2^{\text {nd }} \\
\text { Transistor } \\
\text { activates }\end{array}$ & $\begin{array}{l}3^{\text {rd }} \\
\text { Transistor } \\
\text { activates }\end{array}$ & $\begin{array}{l}4^{\text {th }} \\
\text { Transistor } \\
\text { activates }\end{array}$ \\
\hline $\begin{array}{l}\text { Green of } \\
1^{\text {st }} \text { lane }\end{array}$ & $\begin{array}{l}\text { Green of } \\
2^{\text {nd }} \text { lane }\end{array}$ & $\begin{array}{l}\text { Green of } \\
3^{\text {rd }} \text { lane }\end{array}$ & $\begin{array}{l}\text { Green of } \\
4^{\text {th }} \text { lane }\end{array}$ \\
\hline $\begin{array}{l}\text { Yellow of } \\
2^{\text {nd }} \text { lane }\end{array}$ & $\begin{array}{l}\text { Yellow of } \\
3^{\text {rd }} \text { lane }\end{array}$ & $\begin{array}{l}\text { Yellow of } \\
4^{\text {th }} \text { lane }\end{array}$ & $\begin{array}{l}\text { Yellow of } \\
1^{\text {st }} \text { lane }\end{array}$ \\
\hline $\begin{array}{l}\text { Red of } \\
2^{\text {nd }} \text { lane }\end{array}$ & $\begin{array}{l}\text { Red of } \\
1^{\text {st }} \text { lane }\end{array}$ & $\begin{array}{l}\text { Red of } \\
2^{\text {nd }} \text { lane }\end{array}$ & $\begin{array}{l}\text { Red of } \\
2^{\text {nd }} \text { lane }\end{array}$ \\
\hline $\begin{array}{l}\text { Red of } \\
3^{\text {rd }} \text { lane }\end{array}$ & $\begin{array}{l}\text { Red of } \\
3^{\text {rd }} \text { lane }\end{array}$ & $\begin{array}{l}\text { Red of } \\
1^{\text {st }} \text { lane }\end{array}$ & $\begin{array}{l}\text { Red of } \\
3^{\text {rd }} \text { lane }\end{array}$ \\
\hline $\begin{array}{l}\text { Red of } \\
4^{\text {th }} \text { lane }\end{array}$ & $\begin{array}{l}\text { Red of } \\
4^{\text {th }} \text { lane }\end{array}$ & $\begin{array}{l}\text { Red of } \\
4^{\text {th }} \text { lane }\end{array}$ & $\begin{array}{l}\text { Red of } \\
1^{\text {st }} \text { lane }\end{array}$ \\
\hline $\begin{array}{l}\text { Rt. green } \\
\text { of } 1^{\text {st }} \text { lane }\end{array}$ & $\begin{array}{l}\text { Rt. green } \\
\text { of } 1^{\text {st }} \text { lane }\end{array}$ & $\begin{array}{l}\text { Rt. green } \\
\text { of } 1^{\text {st }} \text { lane }\end{array}$ & $\begin{array}{l}\text { Rt. green } \\
\text { of } 4^{\text {th }} \text { lane }\end{array}$ \\
\hline $\begin{array}{l}\text { Rt. green } \\
\text { of } 4^{\text {th }} \text { lane }\end{array}$ & $\begin{array}{l}\text { Rt. green } \\
\text { of } 2^{\text {nd }} \text { lane }\end{array}$ & $\begin{array}{l}\text { Rt. green } \\
\text { of } 2^{\text {nd }} \text { lane }\end{array}$ & $\begin{array}{l}\text { Rt. green } \\
\text { of } 2^{\text {nd }} \text { lane }\end{array}$ \\
\hline $\begin{array}{l}\text { Rt. green } \\
\text { of } 3^{\text {rd }} \text { lane }\end{array}$ & $\begin{array}{l}\text { Rt. green } \\
\text { of } 4^{\text {th }} \text { lane }\end{array}$ & $\begin{array}{l}\text { Rt. green } \\
\text { of } 3^{\text {rd }} \text { lane }\end{array}$ & $\begin{array}{l}\text { Rt. green } \\
\text { of } 3^{\text {rd }} \text { lane }\end{array}$ \\
\hline
\end{tabular}

Table 4. Traffic light sequence on each lane at a given time

\begin{tabular}{|c|c|c|c|}
\hline$\underset{A}{\text { LANE }}$ & $\underset{B}{\text { LANE }}$ & $\underset{\mathrm{C}}{\text { LANE }}$ & $\begin{array}{c}\text { LANE } \\
\text { D }\end{array}$ \\
\hline$\simeq$ & 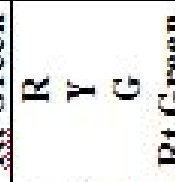 & ש & 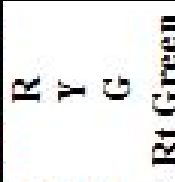 \\
\hline $\begin{array}{lllll}0 & 0 & 1 & 1\end{array}$ & 110 & $\begin{array}{lllll} & 0 & 0 & 1\end{array}$ & $\begin{array}{llll}1 & 0 & 0 & 1\end{array}$ \\
\hline 1001 & $\begin{array}{lll}0 & 0 & 1\end{array}$ & $\begin{array}{llll}1 & 1 & 0 & 0\end{array}$ & $\begin{array}{llll}1 & 0 & 0 & 1\end{array}$ \\
\hline $\begin{array}{llll}1 & 0 & 0 & 1\end{array}$ & 100 & $\begin{array}{llll}0 & 0 & 1 & 1\end{array}$ & $\begin{array}{llll}1 & 1 & 0 & 0\end{array}$ \\
\hline 1100 & 100 & $\begin{array}{llll}1 & 0 & 0 & 1\end{array}$ & $\begin{array}{llll}0 & 0 & 1 & 1\end{array}$ \\
\hline
\end{tabular}

\section{Conclusion and Recommendation}

This project work was aimed at providing a means of pre-empting traffic light signals at a cross junction, which was implemented using simple digital logic devices like ICs which are readily available, easy to use and affordable. To simplify the design system, only one lane was activated with the detection unit though the detection unit could be activated for all the lanes but would make the design cumbersome.

This study was intended to provide a means of pre-empting the normal working condition of traffic light by emergency vehicles and thus has a number of limitations. To further improve the traffic light system, the following recommendations are made:

Providing a means of pre-empting the traffic light on every lane with signal prioritization such that emergency vehicles approaching from different lanes do not change the traffic lights all at the same time causing chaos, but rather one at a time.

Although use of simple digital logic devices could be used to implement the prioritization of the traffic light pre-emption technique, it is recommended that a microcontroller be used as this would simplify and automate the traffic light system.

\section{References}

1. Drive Safely, "The History and Meaning of Colored Traffic Lights". Available: https://www.idrivesafely.com/ defensive-driving/trending/history-and-meaningcolored-traffic-lights. Accessed on 09/05/2018 (2018).

2. BBC, "The man who gave us traffic lights". Available: http://www.bbc.co.uk/nottingham/content/articles/ 2009/07/16/

john_peake_knight_traffic_lights_feature.shtml. Accessed on 09/05/2018 (2009).

3. A. Gardner, "A Brief History of Traffic Lights", https:/ /www.artsy.net/article/artsy-editorial-history-trafficlights. Accessed on 09/05/2018 (2017).

4. Inventorsabout.com, "The History of Roads and Asphalt," http://inventors.about.com/library/ inventors/blasphalt.htm. Accessed on 19/05/2009 (2009).

5. S. M. Gordon, Traffic devices: historical aspects thereof. Washington: Institute of Traffic Engineers, 1971.

6. F.H.W.A.(2005), "System Evolution. Traffic Control 
Systems Handbook,” 2005.

7. D. Bullock, J. Morales, and B. Sanderson, Evaluation of emergency vehicle signal pre-emption, Virginia, (1999).

8. D. N. Bullock and E., Impact Evaluation of Emergency Vehicle Preemption on Signalized Corridor Operation. Washington, D.C: Transportation Research Board, 1 , Presented at (2000).

9. K. D. Hunter-Zaworski and A., "NE Multnomah streetOpticom bus signal priority pilot study," pp.
97-03, (1995).

10. L. L. C. T. Technologies, Digital SirenDetector. Technical Document for Installation. Traffic Technologies, LLC, (2001).

11. T. Webber, Priority 1: GPS-based Fire Pre-emption System.Internal memo. Peoria, Illinois: City of, 9 (2001).

12. F. T. Banerjee, (2001). Transit Priority System for Metro Rapid Bus. Evaluation Report, Department of Transportation, City of Los Angeles, June (2001). 